\title{
Perinatal Post Traumatic Stress Disorder Questionnaire-II (PPQ-II): adaptation, validity, and reliability study
}

\author{
Burcu Komurcu Akik ${ }^{1}$, Aysegul Durak Batigun ${ }^{1}$ \\ ${ }^{1}$ Ankara University, Faculty of Languages History and Geography, Department of Psychology, Sihhiye, Ankara - Turkey
}

\begin{abstract}
Objective: The aim of this study is to adapt the Perinatal Post Traumatic Stress Disorder Questionnaire- II (PPQ-II) and determine the psychometric properties of this scale.

Method: The study was conducted with two different samples consisting of mothers who give full-term and preterm birth. To investigate the factor structure and conduct confirmatory factor analysis, the first sample was composed of 194 women between the ages of 18-43 (Mean=30.12, standard deviation [SD]=4.96). The second sample in which confirmatory factor analysis was conducted consisted of 238 women between the ages of 19-43 (Mean=30.33, SD=4.00). Depression Anxiety Stress Scale and Connor-Davidson Resilience Scale were used in this study as well as PPQ-II.

Results: The exploratory and confirmatory factor analysis revealed a two-factor structure named "Intrusive Thoughts and Avoidance" and "Hyperarousal and Numbness Responses". The model obtained by confirmatory factor analysis demonstrated acceptable goodness of fit values and the questionnaire was found to have satisfactory reliability and validity values.

Conclusion: PPQ-II could be considered as a valid and reliable scale which could be used in maternal mental health studies conducted in Turkey.
\end{abstract}

Keywords: Factor analysis, perinatal trauma, PTSD, reliability, validity

\section{INTRODUCTION}

Although the experience of giving birth, having a baby and transition to motherhood has a significant place in the lives of many women, these can be traumatic for some women (1). Defined as "la nevrose traumatique post-obstetricale" by Bydlowski and Raoul-Duval (2) in the literature, the term perinatal trauma was used for prolonged births, difficult births and birth defects or stillbirths. Many studies from 1978 to the present have revealed that women may experience traumatic symptoms such as nightmares about childbirth, sudden intrusive and disturbing thoughts about childbirth, missing fragments in memories for the moment of birth, and confusion (3-5). Although there are many studies about the postpartum process, it has been recently that perinatal trauma has been examined directly and perinatal post-traumatic stress disorder (PTSD) has begun to be seen as a problem related to the birth experience (6). In the literature, different

How to cite this article: Komurcu Akik B, Durak Batigun A. Perinatal Post Traumatic Stress Disorder Questionnaire-II (PPQ-II): adaptation, validity, and reliability study. Dusunen Adam The Journal of Psychiatry and Neurological Sciences 2020;33:340-350.

Correspondence: Burcu Komurcu Akik, Ankara University, Faculty of Languages History and Geography, Department of Psychology, Sihhiye, 
expressions such as postpartum PTSD, birth-related PTSD, PTSD about birth, PTSD regarding childbirth, birth-induced PTSD, postnatal PTSD are also used in the literature. PTSD is the result of a traumatic event that is gathered in four basic symptom clusters: 1) re-experiencing the traumatic event, 2) avoiding reminders of the traumatic event, 3) excessive arousal / irritability following the traumatic event and 4) negative changes in cognition and affect, is defined as these symptoms last for at least one month and the impairment in functionality (7). The term "traumatic" is defined as a life-threatening experience that causes helplessness and vulnerability in the individual and exceeds the individual's coping abilities (8). While events that play a role in the emergence of acute stress disorder or PTSD can be considered as possible traumatic stressors for everyone (e.g. fire, earthquake, loss of a loved one, being in a battle environment, etc.), childbirth experience or negative experiences around childbirth are not experiences that can be traumatic for everyone. Although childbirth differs from other traumatic events in that not all women have a traumatic experience (9), studies show that many women see delivery as traumatic $(10,11)$. According to studies, it has been reported that $9 \%$ of women who give birth are diagnosed with perinatal PTSD and $18 \%$ are at risk for diagnosis $(12,13)$, in other countries this rate may rise up to $21.5 \%$ (14). It has been observed that the prevalence of perinatal PTSD is higher in high-risk samples such as premature birth, cesarean section, serious complications during pregnancy or delivery (13,15-19). Similarly, it has been shown that mothers with a preterm baby experience more post-traumatic stress symptoms, the symptoms persist until the first years after birth, and are more permanent than mothers of full-term and healthy babies (20-24).

The effects of perinatal trauma far exceed the above-mentioned clinical presentation and prevalence rates. It can be stated that perinatal trauma creates a risk factor for maternal-infant health by affecting women's maternal experiences and their interactions with their babies (25-28). Studies have shown that perinatal trauma has serious and long-term effects on women's relationships with their spouses and babies (25), interrupts the establishment of mother-infant bond (26), but, perinatal trauma is associated with avoidant attachment style (27) and disruptions in mother-infant interaction (28). For example, PTSD symptoms that the mother experiences after birth, such as avoidance, emotional numbness or hyperarousal may cause the mother to stay away from her baby, to be inaccessible to the baby, or to be more intrusive towards her baby at the other extreme (29). It is clear that perinatal trauma or perinatal PTSD should not be overlooked due to the risks it poses in terms of mother and baby health. However, it has been shown that women with perinatal PTSD can rarely be detected and treated, as there are still great difficulties in recognizing perinatal PTSD and it is not routinely screened in the postpartum period (30). At this point, it becomes important to be able to accurately detect and evaluate perinatal trauma.

The first point to be emphasized when evaluating perinatal PTSD is that some situations experienced by women with perinatal PTSD after birth can be overlooked by evaluating as usual (for example, interpreting the mother's turn away from voices as a reaction to hearing the baby's voice). The second point to focus on is what diagnostic criteria to use for perinatal PTSD. It is known that significant changes were made in terms of PTSD diagnostic criteria between the fourth edition of the American Psychiatric Association Diagnostic and Statistical Manual (DSMIV-TR) and the fifth edition (DSM-5) (7,31). Although these changes has been made based on research evidence and clinical observations (32), it causes controversy in the literature due to the complexity of criteria in terms of clustering and differences in the diagnosis of PTSD $(33,34)$. It can be said that the diagnosis of perinatal PTSD, which is more difficult to evaluate than PTSD, has become more complex with the changes made in DSM. However, when the objective is to evaluate perinatal trauma symptoms, it is stated that much more important to be able to make a general measurement of trauma experiences related to birth (35).

The PPQ-II discussed in this study for the assessment and determination of perinatal PTSD risk, is derived from the PPQ, which was developed to identify post-traumatic stress symptoms in mothers with highrisk babies and originally included two Yes/No answer options. This scale was created by converting PPQ's response options to 4-point Likert-type form in order to improve clinical outcomes and measure post-traumatic stress symptoms, including negative cognitions and mood related to birth experience such as disturbing intrusive thoughts, re-living, avoidance behaviors, hyperarousal, numbness, and feelings of guilt (36). Although PPQ-II is not used as a diagnostic criterion alone, it is a scale that allows us to evaluate the perinatal PTSD symptom level. Although the scale was developed on the basis of DSM-III-R, it meets the PTSD 
conceptualization framework in DSM-IV-TR (36-38) and includes items that measuring PTSD symptom clusters specified in DSM-5.

In a limited number of studies on perinatal trauma in our country, it is observed that classical PTSD scales such as Posttraumatic Diagnostic Scale and Impact of Event Scale are used to assess PTSD symptoms related to childbirth (39-44). While studies support that the Posttraumatic Diagnostic Scale is an effective screening criterion for the evaluation of PTSD associated with childbirth in postpartum women, it also suggests that the scale was developed according to DSM-IV diagnostic criteria was a limitation (39-42). The Impact of Event Scale was found to be used in two studies to examine the risk factors associated with the postpartum post-traumatic stress symptoms in our country and to examine the effects of prenatal education on fear of childbirth, self-efficacy and perinatal PTSD symptoms $(43,44)$. According to the DSM-IV, the Impact of Event Scale used in the literature to measure perinatal trauma, measures only three clusters among the PTSD symptoms and can be associated with underestimation of PTSD dimension associated with childbirth $(45,46)$. However, studies in the literature show that the psychometric properties of PPQ and PPQ-II, which are facilitated by increasing the response options, are sufficient and frequently used to measure perinatal trauma (22,36-38,47-50). From this point of view, it was aimed to adapt PPQ-II to Turkish and to examine the psychometric properties of the scale within the scope of this study. It is thought that this study, which evaluates the psychometric properties of PPQ-II, which allows perinatal trauma to be evaluated both samples consisting of mothers who gave preterm and full-term birth, will make a functional contribution to the gap in the literature and that the scale will be useful for clinical research and applications in our country or across cultures.

\section{METHOD}

In order to examine the psychometric characteristics of PPQ-II, the sample of the study was made up by mothers whose babies were between 1-18 months, who had premature birth and whose babies were kept in the incubator, and mothers who gave birth on time and their babies not in the incubator. Mothers of babies born at term and staying in the NICU/incubator for any reason and mothers of babies born prematurely but never staying in the NICU/incubator were excluded from the study.

\section{Sample-I}

The sample consisted of mothers who gave birth prematurely (gestation $<37$ weeks) and whose babies were kept in an incubator (babies between 1-18 months). Since the data of 9 participants out of 203 participants who gave birth prematurely and whose babies were kept in the incubator was the outlier, they were excluded from the data set and the analyzes were carried out on a sample of 194 people aged between 18-43 (Mean=30.12, standard deviation $[\mathrm{SD}]=4.96)$. Eight participants did not report their age. The data of the participants who stated that they had a psychiatric diagnosis or whose babies had congenital disorders were not included in the analysis. For PPQ-II, Exploratory Factor Analysis (EFA) and Confirmatory Factor Analysis (CFA) were performed in the sample of mothers who gave premature birth and whose baby kept in the incubator.

\section{Sample-II}

It consists of 250 mothers (babies were between 1-18 months old) who gave birth on time and whose babies were not in an incubator. Since the data of 12 participants were outliers, CFA analysis was carried out on a sample of 238 people by removing them from the data set. Participant were between 19-43 (Mean=30.33, $\mathrm{SD}=4.00$ ). Three participants did not report their age. The data of participants who stated that they had a psychiatric diagnosis or whose babies had congenital disorder were not included in the analysis. The demographic characteristics of the participants are given in Table 1. For PPQ-II, only CFA was performed in this sample.

\section{Measures}

Demographic Information Form: It was applied to obtain information about demographic characteristics of the participants such as their age, education and income levels, residence, occupational status, psychiatric diagnosis and treatment information.

Perinatal Post Traumatic Stress Disorder Scale-II (PPQ-II): Developed by De Mier et al. (51) and Quinnell and Hynan (38), this scale was later revised by Callahan et al. (36) and named as the Perinatal Post Traumatic Stress Disorder Scale-II (PPQ-II). The scale consists of 14-items and 3-sub-scales measuring posttraumatic symptoms related to the birth experience such as disturbing intrusive thoughts, re-experiencing, avoidant behaviors, hyper-arousal, numbness, and guilt. The first 3 items indicate intrusive thoughts, following six items avoidant behaviors or numbness responses sand the last five items indicate hyperarousal. Response 
Table 1: Descriptive information on demographic characteristics of the sample

\begin{tabular}{|c|c|c|c|c|}
\hline \multirow[b]{2}{*}{ Variables } & \multicolumn{2}{|c|}{$\begin{array}{l}\text { Sample I } \\
(n=194)\end{array}$} & \multicolumn{2}{|c|}{$\begin{array}{l}\text { Sample II } \\
(n=238)\end{array}$} \\
\hline & Range & Mean (SD) & Range & Mean (SD) \\
\hline \multirow[t]{2}{*}{ Age of mother $(n=186 ; 235)$} & $18-43$ & $30.12(4.96)$ & $19-43$ & $30.33(4.00)$ \\
\hline & $\mathbf{n}$ & $\%$ & $\mathbf{n}$ & $\%$ \\
\hline \multicolumn{5}{|l|}{ Level of education } \\
\hline Primary school & 28 & 14.4 & 13 & 5.5 \\
\hline High school & 43 & 22.2 & 33 & 13.9 \\
\hline University and above & 123 & 63.5 & 192 & 80.6 \\
\hline \multicolumn{5}{|l|}{ Monthly income } \\
\hline Low & 27 & 13.9 & 28 & 11.7 \\
\hline Middle & 116 & 59.8 & 122 & 51.3 \\
\hline High & 49 & 25.2 & 88 & 36.9 \\
\hline \multicolumn{5}{|l|}{ Residence } \\
\hline Metropol & 113 & 58.2 & 146 & 61.9 \\
\hline City & 37 & 19.1 & 49 & 20.8 \\
\hline Town/Village & 43 & 22.1 & 41 & 17.4 \\
\hline \multicolumn{5}{|c|}{ Occupational status before giving birth } \\
\hline Yes & 104 & 53.6 & 173 & 72.7 \\
\hline No & 89 & 45.9 & 64 & 26.9 \\
\hline \multicolumn{5}{|l|}{ Current occupational status } \\
\hline Yes & 50 & 25.8 & 109 & 45.8 \\
\hline No & 142 & 73.2 & 128 & 53.8 \\
\hline
\end{tabular}

SD: Standard deviation, Sample I: Mothers who gave premature birth and whose babies kept in the incubator, Sample Il: Mothers who gave birth on time and whose babies did not keep in the incubator

options in PPQ-II were converted to 5-point Likert type scored between 0-4 instead of binary options (Yes, No) in the original form. Mothers were asked to answer the questions in a way that reflects their experiences lasting more than a month between 4 and 18 months after giving birth. The scores to be obtained from PPQ-II range between 0 and 56 . The internal consistency coefficient of the scale was found to be 0.90 . In the differential validity study, it was found that the scale could distinguish the mothers of high-risk babies (medically vulnerable and premature) and the term babies. In addition, when the consistency validity of PPQ-II was examined, it was found that it had a significant relationship with the Impact Event Scale and the Beck Depression Scale Inventory. It was determined that those who score above 19 points from the scale distinguish mothers in need of psychotherapy (36).

Depression Anxiety Stress Scale (DASS): Developed by Lovibond and Lovibond (52), DASS-42 is a 4 -point Likert-type scale ( $0=$ Not suitable for me at all, $3=$ Completely suitable for me). DASS has a total of 42 items, 14 of which are for depression, 14 are for anxiety and 14 are for stress dimensions. The total scores of the scale range from 0 to 42 for each subdimension. In the Turkish adaptation study of DASS, the Cronbach's alpha internal consistency coefficients were 0.89 for the entire scale, $0.90,0.92$, and 0.92 for depression, anxiety, and stress subscales, respectively (53). The higher sample scores in one of these dimensions indicate that the individual has difficulties in the relevant field.

Connor-Davidson Psychological Resilience Scale (CD-RISC): The CD-RISC consists of 25 questions in a 5 -point Likert type ( $0=$ Not true at all, $4=$ Always true) (54). Item 2 is not included in the total score in the Turkish form of the scale. The score that can be obtained from the scale is between 0 and 96. A high score indicates a higher level of psychological resilience. The Turkish form of the scale consists of three subscales. Cronbach's alpha internal consistency coefficients were found to be 0.93 for the perseverance and personal competence subscale, 0.79 for the negative emotion tolerance subscale, and 0.50 for the spirituality spiritual disposition subscale (55). 


\section{Procedure}

Ethical permission was obtained from Ankara University Ethics Committee for conducting the study (Decision No: 56786525-050.04.04/13428, Date: 19/02/2018, No: 03/32). The scale was translated from English to Turkish by the first author. Afterwards, the translation of the scale was evaluated in terms of grammatical compliance, language and comprehensibility (appearance validity) by a team of 15 experts, consisting of 12 psychologists, one associate professor and two professors, who are proficient in both languages. The scale, which was finalized after corrections from experts, was translated into English by an independent expert translator. The back translation form was sent to Prof. Dr. Michael T. Hynan, one of the authors of the original scale, and after receiving the feedback that the translation was quite good compared to the original form of the scale, the data collection phase was started.

Verbal and written information about the research was provided to the participants prior to the process and it confirmed by all. Participants voluntarily took part in the study. Data were collected from mothers residing in Ankara and those who applied to the Neonatology Clinic, Department of Child Health and Diseases, Ankara University Faculty of Medicine. Department of Pediatrics. Data were collected by the researcher using face-to-face or online scale batteries. The application took approximately 30 minutes. SPSS 23.00 and AMOS 22.00 package programs were used for statistical analysis of the data.

\section{RESULTS}

Before the statistical analysis phase of the study, missing data analysis was performed. The mean assignment method was used to ensure that the missing did not exceed 5\% and showed a random distribution (56). For the normal distribution assumption, kurtosis and skewness parameters were set within \pm 2 values $(57,58)$. The Box Plot, Q-Q plots and histogram curves were used to evaluate and determine to outliers and they were excluded from the analysis. After observing that the data set met the multivariate parametric analysis criteria, the analyzes were started. While evaluating the fit of the proposed model, values of $\chi^{2} / \mathrm{df}, \mathrm{CFI}, \mathrm{GFI}$, IFI and RMSEA and BIC were taken into consideration. It is recommended to use multiple fit statistics to evaluate model fit (59). $\chi^{2} / \mathrm{df}$ ratio below $3, \mathrm{CFI}, \mathrm{GFI}$ and IFI at 0.90 and above, and RMSEA value below 0.08 are regarded to be acceptable compliance indices whereas IFI and CFI values 0.95 and above, and finally the RMSEA value below 0.05 are considered as good fit indices (60-62). However, given any of the two predicted models, if the $\mathrm{BIC}$ value is used as the criterion, the model with the lower BIC value is the preferred model (63).

\section{PPQ-II Construct Validity - Exploratory Factor Analysis (EFA) Findings}

In order to determine the construct validity of the scale, for the scale form consisting of 14 items, EFA was performed on a sample of mothers who had a preterm delivery and whose baby was kept in the incubator. Before the factor analysis, the KaiserMeyer-Olkin (KMO) value was checked in order to test the compatibility of the correlation matrix between the items for factor analysis, and it was found that this value was appropriate to continue factor analysis with a value of 0.90 (64). In addition, according to the Bartlett Sphericity test, it was found that the data showed a significant difference $\left(\chi^{2}=1078.74, \mathrm{df}=91\right.$, $\mathrm{p}<0.001)$. Therefore, factor analysis was applied according to principal components method and direct oblimin rotation. As a result of the first analysis performed without determining the number of factors, 2 factors with eigenvalues above 1 were obtained. Since the original form of the scale indicated 3 factors, the factor analysis was re-performed by forcing 3 factors. However, since only two items were loaded on the 3rd factor and the scree plot chart suggested two factors with an eigenvalue above 1 , the analysis of the Turkish form of the scale was continued to present a two-factor structure. During the analysis, an item with a loading value below 0.30 (6th item in the original form) was removed and factor analysis was performed again. The final version of the 13 -item scale with item loading value above 0.30 , the items included in each factor, the variance explained by the factors, eigenvalues and Cronbach alpha reliability coefficients are given in Table 2.

As shown in Table 2, the factor loads of the items vary between 0.50 and 0.88 . "Intrusive Thoughts and Avoidance" (6 items) constitutes $12.41 \%$ of the variance and "Hyperarousal and Numbing of Responsiveness" (7 items) $43.60 \%$ of the variance, these two factors explain $56.01 \%$ of the total variance

\section{PPQ-II Construct Validity - Confirmatory Factor Analysis (CFA) Findings}

In order to test whether the two-factor model obtained in EFA is verified or not, two separate CFAs were 
Table 2: PPQ-II Factor Structure

\begin{tabular}{|c|c|c|c|c|}
\hline \multirow[t]{2}{*}{ Items } & \multicolumn{2}{|c|}{$\begin{array}{l}\text { Factor } \\
\text { loadings }\end{array}$} & \multirow[t]{2}{*}{ Communality } & \multirow[t]{2}{*}{$\begin{array}{l}\text { Item } \\
\text { total } \\
\mathbf{r}\end{array}$} \\
\hline & 1 & 2 & & \\
\hline 1. Did you have bad dreams of giving birth or of your baby's hospital stay? & 0.63 & & 0.53 & $0.72^{*}$ \\
\hline 2. Did you have upsetting memories of giving birth or of your baby' hospital stay? & 0.76 & & 0.60 & $0.76^{*}$ \\
\hline $\begin{array}{l}\text { 3. Did you have any sudden feelings as though your baby's birth was happening } \\
\text { again? }\end{array}$ & 0.77 & & 0.52 & $0.69 *$ \\
\hline 4. Did you try to avoid thinking about childbirth or your baby's hospital stay? & 0.72 & & 0.49 & $0.70^{*}$ \\
\hline $\begin{array}{l}\text { 5. Did you avoid doing things that might bring up feelings you had about } \\
\text { childbirth or your baby's hospital stay (for example, not watching a TV show } \\
\text { about babies)? }\end{array}$ & 0.75 & & 0.60 & $0.78^{*}$ \\
\hline $\begin{array}{l}\text { 6. Did you lose interest in doing things you usually do (for example, did you lose } \\
\text { interest in your work or family)? }\end{array}$ & & 0.74 & 0.56 & $0.37^{*}$ \\
\hline $\begin{array}{l}\text { 7. Did you feel alone and removed from other people (for example, did you feel } \\
\text { like no one understood you)? }\end{array}$ & & 0.66 & 0.60 & $0.43^{*}$ \\
\hline 8. Did it become more difficult for you to feel tenderness or love with others? & & 0.88 & 0.64 & $0.30^{*}$ \\
\hline 9. Did you have unusual difficulty falling asleep or staying asleep? & & 0.62 & 0.47 & $0.23^{* *}$ \\
\hline 10. Were you more irritable or angry with others than usual? & & 0.87 & 0.70 & $0.36^{*}$ \\
\hline 11. Did you have greater difficulties concentrating than before you gave birth? & & 0.76 & 0.64 & $0.36^{*}$ \\
\hline $\begin{array}{l}\text { 12. Did you feel more jumpy (For example, did you feel more sensitive to noise, } \\
\text { or more easily startled)? }\end{array}$ & & 0.50 & 0.41 & $0.27^{*}$ \\
\hline 13. Did you feel more guilt about the childbirth than you felt you should have felt? & 0.60 & & 0.51 & $0.73^{*}$ \\
\hline Explained variance (\%) & 12.41 & 43.60 & 56.01 & \\
\hline Eigenvalue & 1.61 & 5.67 & & \\
\hline Cronbach alfa & 0.83 & 0.87 & 0.89 & \\
\hline
\end{tabular}

${ }^{*} \mathrm{p}<0.001,{ }^{* *} \mathrm{p}<0.01$. Factor 1: Intrusive thoughts and avoidance, Factor 2: Hyperarousal and Numbness Responses

conducted in samples I and II. In the evaluation of CFA, attention was paid to the path diagram and goodness of fit criteria. Error variances of the items were correlated in both analyzes in line with the proposed modification indices. After each error correlation, a chi-square difference test ( $\chi^{2}$ difference test) was conducted (65). After the error correlations, it is seen that the fit indices of the models reached acceptable and good levels $\left(p<0.05\right.$ for $\left.\Delta \chi^{2}\right)$. Fit indices for models before and after error correlations are given in Table 3 .

\section{PPQ-II Criterion-Related Validity Findings}

In the analyzes conducted to evaluate the criterionrelated validity, it was observed that the relationships between variables were in the expected direction. It is seen that the correlation coefficients between the PPQ-II total score and its subscales and depression ranged from 0.40 to $0.63(\mathrm{p}<0.001)$. The correlation coefficients between PPQ-II total score and subscales and anxiety were between 0.39 and $0.61(\mathrm{p}<0.001)$. The correlation coefficients between PPQ-II total score and subscales and stress ranged from 0.45 to $0.63(\mathrm{p}<0.001)$, whereas the correlation coefficients between psychological resilience ranged between -0.14 and $-0.18(\mathrm{p}<0.05)$ (see Table 4$)$.

\section{PPQ-II Differential Validity Findings}

In order to obtain more information about the validity of the scale, end group analyzes were conducted in which individuals with low and high depression, anxiety, stress and CD-RISC scores were compared between the PPQ-II total score and the scores obtained from the sub-dimensions. For this purpose, those who scored one standard deviation high from the mean scores of the relevant variables (depression, anxiety, stress, psychological resilience) and those who scored one standard deviation low were grouped as "high" and "low". The results of the t-test analysis are presented in Table 5.

As can be seen in Table 5, individuals with high scores in depression, anxiety and stress variables get significantly higher scores in PPQ-II total and subscales than individuals with low scores. On the other hand, it 
Table 3: PPQ-II Fit index values

\begin{tabular}{|c|c|c|c|c|c|c|c|c|}
\hline Sample I & $\chi^{2}$ & df & $\chi^{2} / \mathrm{df}$ & CFI & GFI & IFI & RMSEA & BIC \\
\hline Model 1 & 153.10 & 64 & 2.39 & 0.91 & 0.89 & 0.91 & 0.08 & 295.33 \\
\hline Model 2 (m. 9 - 11) & 133.51 & 63 & 2.12 & 0.93 & 0.90 & 0.93 & 0.08 & 281.01 \\
\hline Model 3 (m. 2 - 13) & 123.97 & 62 & 2.00 & 0.94 & 0.91 & 0.94 & 0.07 & 276.74 \\
\hline Sample II & $\chi^{2}$ & df & $\chi^{2} / \mathbf{d f}$ & CFI & GFI & IFI & RMSEA & BIC \\
\hline Model 1 & 163.14 & 64 & 2.55 & 0.91 & 0.91 & 0.91 & 0.08 & 310.89 \\
\hline Model 2 (m. 2 - 13) & 148.45 & 63 & 2.36 & 0.92 & 0.92 & 0.92 & 0.08 & 301.68 \\
\hline Model 3 (m. 1 - 3) & 137.82 & 62 & 2.22 & 0.93 & 0.92 & 0.93 & 0.07 & 296.51 \\
\hline
\end{tabular}

$\chi^{2}$ : Chi-square, df: degrees of freedom, CFI: Comparative Fit Index, GFI: Goodness of Fit Index, IFI: Incremental Fit Index, RMSEA: Root Mean Square Error of Approximation, BIC: Bayesian Information Criterion

Table 4: Correlation coefficients between variables

\begin{tabular}{lcccc} 
& Depression & Anxiety & Stress & CD-RISC \\
\hline PPQ-II & $0.63^{* *}$ & $0.61^{* *}$ & $0.63^{* *}$ & $-0.18^{*}$ \\
Factor 1 & $0.46^{* *}$ & $0.50^{* *}$ & $0.45^{* *}$ & $-0.14^{*}$ \\
Factor 2 & $0.40^{* *}$ & $0.39^{* *}$ & $0.36^{* *}$ & $-0.15^{*}$
\end{tabular}

${ }^{*} \mathrm{p}<0.05,{ }^{* *} \mathrm{p}<0.001$, Factor 1 : Intrusive thoughts and avoidance, Factor 2: Hyper-arousal and numbness responses, PPQ-II: Perinatal Post Traumatic

Stress Disorder Questionnaire-II, CD-RISC: Connor-Davidson Resilience Scale

is observed that individuals with high CD-RISC score significantly lower than PPQ-II total score compared to individuals with low psychological CD-RISC. There is no significant difference between the groups with low and high psychological resilience in terms of PPQ subscales.

\section{PPQ-II Reliability Findings}

Cronbach alpha reliability coefficients of PPQ-II were 0.89 for the total score of the scale, 0.83 for the "Factor 1 " sub-dimension, and 0.87 for the "Factor 2" subdimension. In addition, the correlation coefficient (Guttman Split-Half Coefficient reliability coefficient) between the two half tests formed from odd and even items of the scale according to the split-half method was determined as 0.84 . Item-total correlations were also evaluated for more information on the reliability of the scale (see Table 2). These correlation coefficients varied between $0.69(\mathrm{p}<0.001)$ to $0.78(\mathrm{p}<0.001)$ for Factor 1 subscale, and $0.23(\mathrm{p}<0.01)$ and $0.43(\mathrm{p}<0.001)$ for Factor 2. The relationships between the total scores and items of all subscales were in the expected direction and were significant.

\section{DISCUSSION}

EFA was performed to determine the construct validity of PPQ-II developed by Callahan et al. (36), of which Turkish adaptation study was conducted in this study.
The KMO coefficient (0.90) and Bartlett Sphericity test $\left(\chi^{2}=1078.74, \mathrm{df}=91, \mathrm{p}<0.001\right)$ showed that the data were appropriate for factor analysis (64). Factor analysis based on principal component analysis and direct oblimin rotation indicates that the scale has a two-factor structure consisting of 13 items: "Intrusive Thoughts and Avoidance" and "Hyperarousal and Numbness Responses". The factor loads of all items are between 0.50 and 0.88 , and the two determined factors explain $56.01 \%$ of the total variance.

To determine whether the two-factor structure obtained from EFA was verified, two separate CFAs were performed by applying Bootstrap Maximum Likelihood for corrected estimates using 2000 resampling and 95\% confidence interval in samples of mothers who both gave full-term birth and whose babies were not kept in the incubator, and who gave preterm birth and whose babies were kept in the incubator. CFA results showed that the scale had an acceptable fit index $(61,62)$ for both samples of preterm babies' mothers $\left(\chi^{2}=123.97, \mathrm{df}=62, \chi^{2} / \mathrm{df}=2.00, \mathrm{p}<0.001\right.$, $\mathrm{CFI}=0.94, \mathrm{GFI}=0.91$, IFI $=0.94$, RMSEA $=0.07$, $\mathrm{BIC}=276.74)$, and for the sample of full-term babies' mothers $\left(\chi^{2}=137.82, \mathrm{df}=62, \chi^{2} / \mathrm{df}=2.22, \mathrm{p}<0.001\right.$, $\mathrm{CFI}=0.93$, GFI $=0.92$, IFI $=0.93$, RMSEA $=0.07$, $B I C=296.51$ ). Low BIC values in the last models associated with errors compared to the previous models also indicate the fit of the model (63).

Evaluating the criterion-related validity of the scale, the fact that the relationship between PPQ-II total score and its subscales with depression, anxiety and stress variables were positive and significant whereas the negative and significant relationship with CD-RISC, provide support to the criterion validity.

When the differential validity of the scale was examined, it was observed that PPQ-II could distinguish individuals with high and low scores from depression, anxiety, stress and CD-RISC scales. 
Table 5: Comparison of the individuals with low and high depression, anxiety, stress and psychological resilience levels in terms of PPQ-II and subscale scores

Depression $<0.63$

Depression $>\mathbf{2 2 . 6 1}$

$n=19$ $n=32$

\begin{tabular}{|c|c|c|c|c|c|}
\hline & \multicolumn{2}{|c|}{$n=19$} & \multicolumn{2}{|c|}{$n=32$} & \multirow[b]{2}{*}{$\mathbf{t}$} \\
\hline & Mean & SD & Mean & SD & \\
\hline PPQ-II & 17.79 & 13.75 & 39.06 & 9.30 & $-5.98^{* * * *}$ \\
\hline Factor 1 & 8.32 & 7.48 & 16.22 & 6.62 & $-3.93^{* * *}$ \\
\hline Factor 2 & 18.79 & 7.46 & 25.40 & 7.08 & $-3.16^{* *}$ \\
\hline
\end{tabular}

Anxiety <3.16

Anxiety $>22.90$

$n=31$

$n=34$

\begin{tabular}{|c|c|c|c|c|c|}
\hline \multirow[b]{2}{*}{ 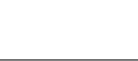 } & \multirow[b]{2}{*}{ Mean } & \multirow[b]{2}{*}{ SD } & & \multirow[b]{2}{*}{$\mathbf{t}$} \\
\hline & & & Mean & SD & \\
\hline PPQ-II & 18.19 & 11.80 & 36.68 & 11.22 & $-6.47^{* * *}$ \\
\hline Factor 1 & 7.45 & 6.04 & 15.79 & 6.00 & $-5.58^{* * * *}$ \\
\hline Factor 2 & 19.35 & 6.40 & 25.35 & 7.50 & $-3.45^{* *}$ \\
\hline
\end{tabular}

Stress $<5.34$

Stress $>\mathbf{2 7 . 9 6}$

\begin{tabular}{|c|c|c|c|c|c|}
\hline & \multicolumn{2}{|c|}{$n=25$} & \multicolumn{2}{|c|}{$n=38$} & \multirow[b]{2}{*}{$\mathbf{t}$} \\
\hline & Mean & SD & Mean & SD & \\
\hline PPQ-II & 16.32 & 13.36 & 35.92 & 10.87 & $-6.39 * * *$ \\
\hline Factor 1 & 7.72 & 6.94 & 14.39 & 6.60 & $-3.85^{* * *}$ \\
\hline Factor 2 & 18.12 & 6.28 & 23.92 & 7.24 & $-3.27^{* *}$ \\
\hline
\end{tabular}

CD-RISC <45.11

CD-RISC $>80.69$

$n=33$

$\mathbf{n}=\mathbf{2 8}$

\begin{tabular}{lccccc} 
& Mean & SD & Mean & SD & t \\
\hline PPQ-II & 28.71 & 13.05 & 21.39 & 14.28 & $2.07^{*}$ \\
Factor 1 & 12.59 & 6.32 & 9.36 & 6.86 & 1.91 \\
Factor 2 & 21.97 & 6.93 & 18.94 & 7.60 & 1.63 \\
\hline
\end{tabular}

${ }^{*} \mathrm{p}<0.05,{ }^{* *} \mathrm{p}<0.01,{ }^{* * *} \mathrm{p}<0.001$, PPQ-II: Perinatal Post Traumatic Stress Disorder Questionnaire-II, Factor 1: Intrusive thoughts and avoidance, Factor 2: Hyper-arousal and numbness responses, PPQ-II: Perinatal Post Traumatic Stress Disorder Questionnaire-II, CD-RISC: Connor-Davidson Resilience Scale

When the reliability findings of PPQ-II are examined, Cronbach alpha reliability coefficients are; 0.89 for the total score, 0.83 for the "Intrusive Thoughts and Avoidance" sub-dimension, and 0.87 for the "Hyperarousal and Numbness Responses" subdimension. Considering that the reliability level suggested for the Cronbach alpha coefficient is 0.70 (66), it is seen that PPQ-II has adequate internal consistency coefficients. The fact that the correlations between the PPQ-II subscales and the item and the total score and subscales of the PPQ-II are in the expected direction and significant also supports the reliability of the scale.

Although PPQ-II is a valid and reliable measurement tool, there are some points that should be paid attention to regarding the psychometric properties of PPQ-II. As mentioned before in the measures section, in the original form of PPQ-II, based on the PTSD definition sets $(B, C, D)$ in DSM-IV, the first three items indicate unwanted intrusive thoughts, and the next six items indicate responses to avoidance or numbness, and the last five items indicate hyper-arousal (36). However, in the Turkish validity study of the scale, it is seen that the distribution of items into factors is different from the original form. In the Turkish version of the scale, the first five and the last items were loaded on the first factor and named as "Intrusive Thoughts and Avoidance (items: 1, 2, 3, 4, 5, 13)", the remaining seven items were loaded on the second factor and named as "Arousal and Numbness Responses (items: 6, 7, 8, 9, 10, 11, 12)". The sixth item in the original form was excluded from the analysis due to its low factor load in the Turkish form, and item 14 (item 13 in the Turkish form) was included in the first factor. Although in the Turkish form of the scale it seems that a single factor was obtained by combining the first two factors in the original form (intrusive thoughts and avoidance) and thus achieved a two-factor structure, it should not be overlooked that the content of the seventh and eighth items in the original form may correspond to the concepts indicated in both factors in the Turkish form. It should be noted 
that this approach, which seems simply rational and statistically correct, will not bring a healthy interpretation in terms of the theoretical background. In other words, it is observed that items belonging to the second factor in the original form of the scale are shared between two factors in the Turkish form; some of the items are in the first factor and some are in the second factor. In addition, although intrusive thoughts and avoidance structures present a similar appearance in terms of their consequences, they are different structures in terms of their occurrence and responses to trauma. Therefore, it is clear that using the total score of the scale will be more successful in reflecting the perinatal post traumatic stress level experienced by the mother. When the studies in which PPQ and PPQ-II are examined in the literature, it is seen that sub-scale scores are used in very few studies $(51,67)$, while the total score was used in many other studies. $(22,35,36,38,48-50,68)$. As stated before, when the objective is to evaluate the trauma symptoms related to childbirth, it is stated that it is much more important to be able to make a general measurement of trauma experiences related to birth, rather than which subscale reflects which cluster (35).

As a result, the analysis conducted reveals that PPQ-II is a valid and reliable scale in measuring the perinatal post-traumatic stress symptoms experienced by the mother. Higher scores from the scale indicate that the symptoms of PTSD related to the childbirth experienced by the mother are high. Validity and reliability analyses show that PPQ-II has sufficient psychometric properties.

\begin{tabular}{|c|c|c|}
\hline \multicolumn{2}{|c|}{ Contribution Categories } & \multirow{2}{*}{$\begin{array}{l}\text { Author Initials } \\
\text { B.K.A., A.D.B. }\end{array}$} \\
\hline \multirow{3}{*}{ Category 1} & Concept/Design & \\
\hline & Data acquisition & B.K.A. \\
\hline & Data analysis/Interpretation & B.K.A., A.D.B. \\
\hline \multirow{2}{*}{ Category 2} & Drafting manuscript & B.K.A. \\
\hline & Critical revision of manuscript & A.D.B. \\
\hline Category 3 & Final approval and accountability & B.K.A., A.D.B. \\
\hline \multirow{2}{*}{ Other } & Technical or material support & $\mathrm{N} / \mathrm{A}$ \\
\hline & Supervision & $\mathrm{N} / \mathrm{A}$ \\
\hline
\end{tabular}

Declaration: This article includes a part of the doctoral dissertation study conducted by Burcu Komurcu Akik under the advisory of Prof. Dr. Ayşegül Durak-Batıgün within the scope of Ankara University Institute of Social Sciences Clinical Psychology Doctoral Program.

Acknowledgement: We thank all the mothers in our study by taking their precious time and sharing their experiences with us.

Ethics Committee Approval: Ethical permission was obtained from Ankara University Ethics Committee for conducting the study (Decision No: 19/02/2018 03/32).
Informed Consent: Informed consent form was obtained from all participants.

Peer-review: Externally peer-reviewed.

Conflict of Interest: The authors declare that they have no conflict of interest.

Financial Disclosure: There is no funding source related to this study.

\section{REFERENCES}

1. Dekel S, Stuebe C, Dishy G. Childbirth induced posttraumatic stress syndrome: a systematic review of prevalence and risk factors. Front Psychol 2017; 8:560. [CrossRef]

2. Bydlowski, M, Raoul-Duval A. A psychological manifestation unknown within paediatrics: The posttraumatic obstetric neurosis. Perspect Psychiatry 1978; 4:321-328.

3. Beech BA, Robinson J. Nightmares following childbirth. Br J Psychiatry 1985; 147:586. [CrossRef]

4. Arizmendi TG, Affonso DD. Stressful events related to pregnancy and postpartum. J Psychosom Res 1987; 31:743-756. [CrossRef]

5. Stolte K. Postpartum 'missing pieces': sequela of a passing obstetrical era? Birth 1986; 13:100-103. [CrossRef]

6. Söderquist J, Wijma K, Wijma B. Traumatic stress after childbirth: the role of obstetric variables. J Psychosom Obstet Gynaecol 2002; 23:31-39. [CrossRef]

7. American Psychiatric Association. Diagnostic and statistical manual of mental disorders, fifth edition. Washington DC: American Psychological Association; 2013.

8. Yehuda R. Post-traumatic stress disorder. N Engl J Med 2002; 346:108-114. [CrossRef]

9. Ayers S, Jessop D, Pike A, Parfitt Y, Ford E. The role of adult attachment style, birth intervention and support in posttraumatic stress after childbirth: a prospective study. J Affect Disord 2014; 155:295-298. [CrossRef]

10. Alcorn KL, O’Donovan A, Patrick JC, Creedy D, Devilly GJ. A prospective longitudinal study of the prevalence of posttraumatic stress disorder resulting from childbirth events. Psychol Med 2010; 40:1849-1859. [CrossRef]

11. Ayers S, Pickering AD. Do women get posttraumatic stress disorder as a result of childbirth? A prospective study of incidence. Birth 2001; 28:111-118. [CrossRef]

12. Beck CT, Gable RK, Sakala C, Declercq ER. Posttraumatic stress disorder in new mothers: results from a two-stage U.S. national survey. Birth 2011; 38:216-227. [CrossRef]

13. Grekin R, O'Hara MW. Prevalence and risk factors of postpartum posttraumatic stress disorder: a meta-analysis. Clin Psychol Rev 2014; 34:389-401. [CrossRef]

14. Schwab W, Marth C, Bergant AM. Post-traumatic stress disorder post partum: the impact of birth on the prevalence of posttraumatic stress disorder (PTSD) in multiparous women. Geburtshilfe Frauenheilkd 2012; 72:56-63. [CrossRef] 
15. Beck CT, Woynar J. Posttraumatic Stress in Mothers While Their Preterm Infants Are in the Newborn Intensive Care Unit: A Mixed Research Synthesis. ANS Adv Nurs Sci 2017; 40:337-355.

16. Helle N, Barkmann C, Ehrhardt S, Bindt C. Postpartum posttraumatic and acute stress in mothers and fathers of infants with very low birth weight: Cross-sectional results from a controlled multicenter cohort study. J Affect Disord 2018;235:467-473. [CrossRef]

17. Shaw JG, Asch SM, Kimerling R, Frayne SM, Shaw KA, Phibbs CS. Posttraumatic stress disorder and risk of spontaneous preterm birth. Obstet Gynecol 2014; 124:1111-1119. [CrossRef]

18. Wenzel A, Haugen EN, Jackson LC, Brendle JR. Anxiety symptoms and disorders at eight weeks postpartum. J Anxiety Disord 2005; 19:295-311. [CrossRef]

19. Yildiz PD, Ayers S, Phillips L. The prevalence of posttraumatic stress disorder in pregnancy and after birth: A systematic review and meta-analysis. J Affect Disord 2017; 208:634-645. [CrossRef]

20. Ahlund S, Clarke P, Hill J, Thalange NK. Post-traumatic stress symptoms in mothers of very low birth weight infants 2-3 years post-partum. Arch Womens Ment Health 2009; 12:261-264.

21. Brandon DH, Tully KP, Silva SG, Malcolm WF, Murtha AP, Turner BS, et al. Emotional responses of mothers of late-preterm and term infants. J Obstet Gynecol Neonatal Nurs 2011; 40:719-731.

22. Feeley N, Zelkowitz P, Cormier C, Charbonneau L, Lacroix A, Papageorgiou A. Posttraumatic stress among mothers of very low birthweight infants at 6 months after discharge from the neonatal intensive care unit. Appl Nurs Res 2011; 24:114-117. [CrossRef]

23. Ghorbani M, Dolatian M, Shams J, Alavi-Majd H, Tavakolian S. Factors associated with posttraumatic stress disorder and its coping styles in parents of preterm and full-term infants. Glob J Health Sci 2014; 6:65-73. [CrossRef]

24. Habersaat S, Borghini A, Nessi J, Pierrehumbert B, Forcada-Guex $\mathrm{M}$, Ansermet F, et al. Posttraumatic stress symptoms and cortisol regulation in mothers of very preterm infants. Stress Health 2014; 30:134-141. [CrossRef]

25. Ayers S, Eagle A, Waring H. The effects of childbirth-related posttraumatic stress disorder on women and their relationships: a qualitative study. Psychol Health Med 2006; 11:389-398. [CrossRef]

26. Dekel S, Thiel F, Dishy G, Ashenfarb AL. Is childbirth-induced PTSD associated with low maternal attachment? Arch Womens Ment Health 2019; 22:119-122. [CrossRef]

27. Hairston IS, Handelzalts JE, Assis C, Kovo M. Postpartum bonding diffıculties and adult attachment styles: the mediatıng role of postpartum depression and childbirth-related PTSD. Infant Ment Health J 2018; 39:198-208. [CrossRef]

28. Petit AC, Eutrope J, Thierry A, Bednarek N, Aupetit L, Saad $S$, et al. Mother's Emotional and Posttraumatic Reactions after a Preterm Birth: the Mother-Infant Interaction Is at Stake 12 Months after Birth. PLoS One 2016; 11:e0151091.

29. Garthus-Niegel S, Ayers S, Martini J, von Soest T, Eberhard-Gran M. The impact of postpartum post-traumatic stress disorder symptoms on child development: a population-based, 2-year follow-up study. Psychol Med 2017; 47:161-170. [CrossRef]
30. Ayers S, Wright DB, Thornton A. Development of a measure of postpartum PTSD: the city birth trauma scale. Front Psychiatry 2018; 9:409. [CrossRef]

31. American Psychiatric Association. Diagnostic and statistical manual of mental disorders, fourth edition. text revision (DSMIV-TR) Washington DC: American Psychological Association; 2000.

32. Weathers FW. Redefining posttraumatic stress disorder for DSM5. Curr Opin Psychol 2017; 14:122-126. [CrossRef]

33. Armour C, Müllerová J, Elhai JD. A systematic literature review of PTSD's latent structure in the Diagnostic and Statistical Manual of Mental Disorders: DSM-IV to DSM-5. Clin Psychol Rev 2016; 44:60-74. [CrossRef]

34. Boorman RJ, Devilly GJ, Gamble J, Creedy DK, Fenwick J. Childbirth and criteria for traumatic events. Midwifery 2014; 30:255-261. [CrossRef]

35. Zerach G, Elsayag A, Shefer S, Gabis L. Long-term maternal stress and post-traumatic stress symptoms related to developmental outcome of extremely premature infants. Stress Health 2015; 31:204-213. [CrossRef]

36. Callahan JL, Borja SE, Hynan MT. Modification of the Perinatal PTSD Questionnaire to enhance clinical utility. J Perinatol 2006; 26:533-539. [CrossRef]

37. DeMier RL, Hynan MT, Hatfield RF, Varner MW, Harris HB, Manniello RL. A measurement model of perinatal stressors: identifying risk for postnatal emotional distress in mothers of high-risk infants. J Clin Psychol 2000; 56:89-100. [CrossRef]

38. Quinnell FA, Hynan MT. Convergent and discriminant validity of the perinatal PTSD questionnaire (PPQ): a preliminary study. J Trauma Stress 1999; 12:193-199. [CrossRef]

39. Dikmen-Yildiz P, Ayers S, Phillips L. Screening for birth-related PTSD: psychometric properties of the Turkish version of the Posttraumatic Diagnostic Scale in postpartum women in Turkey. Eur J Psychotraumatol 2017; 8:1306414. [CrossRef]

40. Dikmen-Yildiz P, Ayers S, Phillips L. Depression, anxiety, PTSD and comorbidity in perinatal women in Turkey: A longitudinal population-based study. Midwifery 2017; 55:29-37. [CrossRef]

41. -Yildiz P, Ayers S, Phillips L. Factors associated with posttraumatic stress symptoms (PTSS) 4-6 weeks and 6 months after birth: A longitudinal population-based study. J Affect Disord 2017; 221:238-245. [CrossRef]

42. Dikmen-Yildiz P, Ayers S, Phillips L. Longitudinal trajectories of post-traumatic stress disorder (PTSD) after birth and associated risk factors. J Affect Disord 2018; 229:377-385. [CrossRef]

43. Isbir GG, Inci F, Bektas M, Dikmen Yildiz P, Ayers S. Risk factors associated with post-traumatic stress symptoms following childbirth in Turkey. Midwifery 2016; 41:96-103. [CrossRef]

44. Gokce Isbir G, Inci F, Onal H, Yildiz PD. The effects of antenatal education on fear of childbirth, maternal self-efficacy and post-traumatic stress disorder (PTSD) symptoms following childbirth: an experimental study. Appl Nurs Res 2016; 32:227232. [CrossRef] 
45. De Schepper S, Vercauteren T, Tersago J, Jacquemyn Y, Raes F, Franck E. Post-Traumatic Stress Disorder after childbirth and the influence of maternity team care during labour and birth: A cohort study. Midwifery 2016; 32:87-92. [CrossRef]

46. Kersting A, Dorsch M, Wesselmann U, Lüdorff K, Witthaut J, Ohrmann P, et al. Maternal posttraumatic stress response after the birth of a very low-birth-weight infant. J Psychosom Res 2004; 57:473-476. [CrossRef]

47. Ionio C, Di Blasio P. Post-traumatic stress symptoms after childbirth and early mother-child interactions: an exploratory study. J Reprod Infant Psychol 2014; 32:163-181. [CrossRef]

48. Forcada-Guex M, Borghini A, Pierrehumbert B, Ansermet F, Muller-Nix C. Prematurity, maternal posttraumatic stress and consequences on the mother-infant relationship. Early Hum Dev 2011; 87:21-26. [CrossRef]

49. Muller-Nix C, Forcada-Guex M, Pierrehumbert B, Jaunin L, Borghini A, Ansermet F. Prematurity, maternal stress and mother-child interactions. Early Hum Dev 2004; 79:145-158.

50. Pierrehumbert B, Nicole A, Muller-Nix C, Forcada-Guex M, Ansermet F. Parental post-traumatic reactions after premature birth: implications for sleeping and eating problems in the infant. Arch Dis Child Fetal Neonatal Ed 2003; 88:F400-404. [CrossRef]

51. DeMier RL, Hynan MT, Harris HB, Manniello RL. Perinatal stressors as predictors of symptoms of posttraumatic stress in mothers of infants at high risk. J Perinatol 1996; 16:276-280.

52. Lovibond PF, Lovibond SH. The structure of negative emotional states: comparison of the Depression Anxiety Stress Scales (DASS) with the Beck Depression and Anxiety Inventories. Behav Res Ther 1995; 33:335-343. [CrossRef]

53. Akin A, Cetin B. The Depression Anxiety and Stress Scale (DASS): The study of validity and reliability. Educational Sciences: Theory and Practice 2007; 7:260-268.

54. Connor KM, Davidson JR. Development of a new resilience scale: the Connor-Davidson Resilience Scale (CD-RISC). Depress Anxiety 2003; 18:76-82. [CrossRef]

55. Karairmak O. Establishing the psychometric qualities of the Connor-Davidson Resilience Scale (CD-RISC) using exploratory and confirmatory factor analysis in a trauma survivor sample. Psychiatry Res 2010; 179:350-356. [CrossRef]
56. Eekhout I, de Vet HC, Twisk JW, Brand JP, de Boer MR, Heymans MW. Missing data in a multi-item instrument were best handled by multiple imputation at the item score level. J Clin Epidemiol 2014; 67:335-342. [CrossRef]

57. Field AP. Discovering statistics using IBM SPSS Statistics: And sex and drugs and rock 'n'roll. Fouth ed., London: Sage, 2013.

58. George D, Mallery P. SPSS for Windows step by step. A Simple study guide and reference Tenth ed., GEN, Boston, MA: Pearson Education, 2010.

59. Kline RB. Principles and practice of structural equation modeling. Fourth ed., NY: Guilford Press, 2015.

60. Byrne BM. Testing for the factorial validity of a theoretical construct. Structural equation modeling with AMOS: Basic concepts, applications, and programming. Second ed., NY: Routledge, 2010.

61. Byrne BM. Structural equation modeling with Mplus: Basic concepts, applications, and programming. NY: Routledge, 2011.

62. Marsh HW, Hau KT, Wen Z. In search of golden rules: Comment on hypothesis-testing approaches to setting cutoff values for fit indexes and dangers in overgeneralizing $\mathrm{Hu}$ and Bentler's (1999) findings. Struct Equ Modeling 2004; 11:320-341. [CrossRef]

63. Wikipedia. Bayesian information criterion. https:// en.wikipedia.org/w/index.php?title=Bayesian_information_ criterion\&oldid=496433604. Accessed September 21, 2020.

64. Worthington RL, Whittaker TA. Scale development research: A content analysis and recommendations for best practices. Couns Psychol 2006; 34:806-838. [CrossRef]

65. Tabachnick BG, Fidell LS. Using multivariate statistics. Sixth ed., Upper Saddle River NJ: Pearson, 2013.

66. Nunnally JC, Bernstein IH. Psychometric theory. Third ed., New York, McGraw-Hill, 1994.

67. Di Blasio P, Ionio C, Confalonieri E. Symptoms of postpartum PTSD and expressive writing: A prospective study. J Prenat Perinat Psychol Health 2009; 24:49-65.

68. Callahan JL, Hynan MT. Identifying mothers at risk for postnatal emotional distress: further evidence for the validity of the perinatal posttraumatic stress disorder questionnaire. J Perinatol 2002; 22:448-454. [CrossRef] 